\title{
The Predictive Strength of Students' Self-Efficacy, Problem Solving Skills to Perform Catheter Care
}

\author{
Dogu Kokcu, Ozlem ${ }^{1 \oplus} \cdot$ Cevik, Celalettin ${ }^{2}$ \\ ${ }^{1}$ Department of Fundamentals of Nursing, Faculty of Health Sciences, Sakarya University, Sakarya \\ ${ }^{2}$ Department of Public Health Nursing, Faculty of Health Sciences, Balikesir University Cagis Campus, Balikesir, Turkey
}

\begin{abstract}
Purpose: The aim of this study was to determine the predictive strength of students' self-efficacy, problem-solving skills, and other characteristics in performing intravenous practices and monitor phlebitis and infiltration. Methods: This cross-sectional study was carried out with 736 third and fourth-year students studying at the Health Sciences Faculties of Balikesir and Sakarya universities. The data were collected using the Self-Efficacy Scale, Problem-Solving Inventory and Catheter Care and Infiltration Monitoring Questionnaire. Results: The participants' mean Catheter Care and Infiltration Monitoring Questionnaire score significantly and positively correlated with their mean Self-Efficacy Scale score on a moderate level $(r=.25 ; p<.001)$ but significantly and negatively correlated with their mean Problem-Solving Inventory score on a moderate level $(r=-.21 ; p<.001)$. In other words, because a low Problem-Solving Inventory score indicates that the person's problem-solving skill is high, the Care and Infiltration Monitoring Questionnaire score increased as the problem-solving skill increased. While the Self-Efficacy Scale predicted the year of study and catheter care and infiltration monitoring variables positively, the Problem-Solving Inventory predicted the satisfaction with the profession variable negatively. Conclusion: Self-efficacy, problem-solving, liking the profession, and year of study predict success in catheter care and infiltration monitoring. For this reason, guidance may be provided in the development of a comprehensive education system toward increasing students' problem-solving skills, self-efficacy, and professional knowledge and skills.
\end{abstract}

Key words: Students; Knowledge; Catheterization, Peripheral; Correlation of Data

\section{INTRODUCTION}

A peripheral intravenous catheter (PIVC) is used to administer medications and fluids or parenteral nutrition. PIVC is a practice that is frequently used in patients who are receiving infusion care, and its use by healthcare professionals who are not properly trained may lead to negative outcomes such as phlebitis, thrombosis, and anxiety in many patients in a short time [1,2]. Several studies suggest that the incidence of phlebitis development is $30.7 \%$ [3]. The causes of phlebitis could be mechanical, chemical, and/or bacterial [4]. As a nursing practice, PIVC is frequently used in healthcare services and requires nurses to have relevant knowledge, skills, self-confidence, self-efficacy, and decision-making and problem-solving skills $[5,6]$.

Self-efficacy is a cognitive-perceptual factor that influences a person's behavior [7]. Individuals with poor self-efficacy not only display poor performance or effort to overcome a challenging case but also have a poor perspective about solving a problem in the best way possible. In other words, their problem-solving skills, which require creative thinking, are poor [8,9]. Personal

Address reprint requests to : Cevik, Celalettin

Department of Public Health Nursing, Faculty of Health Sciences, Balikesir University Cagis Campus, Balikesir 10100, Turkey

Tel: +90-266-244-0010-323Ｆax: +90-266-249-7125_E-mail: celalettincevik@outlook. com

Received: January 3, 2020 Revised: April 16, 2020 Accepted: April 17, 2020 Published online June 1, 2020

This is an Open Access article distributed under the terms of the Creative Commons Attribution NoDerivs License. (http://creativecommons. org/licenses/by-nd/4. 0)

If the original work is properly cited and retained without any modification or reproduction, it can be used and re-distributed in any format and medium. 
characteristics, self-efficacy, problem-solving skills, practice skills, and academic achievement are interrelated concepts $[5,10]$.

Problem-solving is a concept that requires an individual to receive and process information and put this information into practice. Student nurses and student midwives should be able to deal not only with their own problems but also the problems of others. This requires complex and rapid interventions at the hospital where people are vulnerable to stress and acute situations at all times [11]. Problem-solving is also important for nurses because it is a sub-step of critical thinking. Several studies have demonstrated that students are aware of the problems encountered while they are providing care by comparing the knowledge they have obtained during education with the knowledge they have obtained in clinical settings, but they are inadequate in finding solutions [12]. However, what distinguish an autonomous nurse (a nurse who is able to make decisions independently within the framework of tasks) from a non-autonomous nurse (a nurse who is not able to do so), or an experienced nurse from an inexperienced nurse, are critical thinking and problem-solving skills [13]. Although some studies were conducted to try and explain the skills of nurses or students in terms of evidence-based practices focusing on factors such as critical thinking and problem-solving skills, there are no studies in which two important components of PIVC application, namely problem-solving skills and self-efficacy, are investigated together $[5,8,9,11,14,15]$.

Therefore, this study aimed to find out whether several variables such as students' self-efficacy and problem-solving skills may predict their knowledge of and responsibility for performing intravenous practices and monitoring phlebitis and infiltration. The researcher believes that the study contributes to developing strategies to facilitate learning.

\section{METHODS}

\section{Study design}

This study was a cross-sectional study.

\section{Setting and samples}

The population of the study comprised third- and fourth-year students studying at the Health Sciences Faculties of Balikesir and Sakarya universities. The sample size was calculated as 736 in the G*power 3.1 program [16]. The power, effect size, and type I error for the calculations were $99.0 \%, 0.2$, and $1.0 \%$, respectively. Systematic sampling was used as the sampling method.

\section{Data collection and procedure}

The data were collected by the researchers at the end of class hours on scheduled dates. Before the data collection, the students were informed about the objective and scope of the study and were asked whether they would volunteer to participate in the study. The participants completed the questionnaires in approximately ten minutes. During the data collection process, $102 \mathrm{stu}-$ dents were excluded from the study. Of these, 52 (7.1\%) refused to participate in the study, $23(3.1 \%)$ did not attend the classes, and $27(3.7 \%)$ filled in the questionnaires incompletely or incorrectly. However, instead of these 102 students, 102 other students were enrolled in the study, and the sample size that was calculated as 736 was maintained. The questionnaires were then handed out to all participants. All the participants returned the questionnaires after completing them. The participation rate was $86.1 \%$.

\section{Variables}

The data were collected using a Personal Information Form, the Self-Efficacy Scale (SES), the Problem-solving Inventory Scale (PSI) and the Catheter Care and Infiltration Monitoring Questionnaire (CCIMQ).

\section{Measurements and instruments}

\section{1) Personal information form}

The form, prepared by the researcher in the light of the literature, consisted of 15 items asking the participants' about their sociodemographic characteristics such as age, education level, gender, etc.

\section{2) Self-efficacy scale}

The 14-item SES was developed by Sherer et al. [17] in 1982 to measure the general self-efficacy perceptions of an individual. The responses to the items are rated on a four-point Likert-type scale. However, Sherer and Adams [18] converted the scale into a 23 -item scale in 1983. The responses to the 23 items are rated 
on a five-point Likert-type scale ranging from 1 (strongly disagree) to 5 (strongly agree). This 23-item scale was adapted to the Turkish setting by Gözüm [19]. The minimum and maximum possible scores that can be obtained from the scale are 23 and 115, respectively. Higher scores indicate that the person's perception of self-efficacy is greater. In the validity study of the 23item scale, the Cronbach's $\alpha$ coefficient was calculated as .82 for the "starting to display the behavior" subscale, .77 for the "maintaining the behavior" subscale, 79 for the "completing the behavior" subscale, .64 for the "struggling against barriers" subscale and .81 for the overall SES [19]. In this study, the Cronbach's $\alpha$ coefficient was calculated as .84 for the overall SES, .80 for the "starting to display the behavior" subscale, .70 for the "maintaining the behavior" subscale, .86 for the "completing the behavior" subscale and .72 for the "struggling against barriers" subscale.

\section{3) Catheter care and infiltration monitoring questionnaire}

The CCIMQ was developed by the researchers to determine students' knowledge of and responsibility for intravenous administration, phlebitis, and monitoring of infiltration. In the literature, there is no scale on catheter care and infiltration monitoring whose validity and reliability study was performed for the Turkish society. Therefore, the researchers developed a 14-item CCIMQ based on the relevant literature $[3,5,6]$. The items in the CCIMQ focus on the points to consider during the insertion of PIVCs and the prevention of the development of catheter-induced phlebitis and infiltration. The 14-item CCIMQ, which was developed based on the pertinent literature, was used to measure students' catheter care knowledge levels. The items focused on the following: preparations prior to performing the procedure, communication, identity check, information and education before performing the procedure, environment, hygiene, performing venipuncture or inserting a peripheral venous catheter, and documentation. A pilot study was then carried out with 24 individuals who were not part of the sample. Based on their feedback, necessary revisions were made on the questionnaire; then, the data were collected [20]. The responses to the items had three options: yes, no, and undecided. The "yes" answers were scored as "1", while the "no" answers were scored as "0," which yielded the knowledge score. The items with the "undecided" responses were not included in the scoring process. Higher scores indicated higher levels of knowledge of catheter care and infiltration monitoring. The reliability test showed that the Cronbach's $\alpha$ value for the CCIMQ was .77, that is, greater than 70 [21], indicating that the survey results had high reliability.

\section{4) Problem-solving inventory}

The PSI was developed by Heppner and Petersen [22]. It is used to assess what people think about their own problem-solving behaviors and approaches. The scale has 35 items and three subscales. The reliability and validity study of the Turkish version of the scale was conducted by Taylan [23]. Low scores indicated effectiveness and success in problem-solving, while high scores indicated that the participants could not find effective solutions to problems. In the validity study of the scale, the Cronbach's $\alpha$ coefficient was .82 for the "confidence" subscale, .77 for the "approach/avoidance" subscale, .79 for the "personal control" subscale and .81 for the overall PSI [23]. In this study, the Cronbach's coefficient was .80 for the "confidence" subscale, .72 for the "approach/avoidance" subscale, .70 for the "personal control" subscale and .78 for the overall PSI.

\section{Data analysis}

The variables are summarized as frequencies, means, and percentages. The Shapiro Wilk test was used to verify the normal distribution of the observed data. Regression analysis was used to explain the relationships. All the results of the calculations and the data were analyzed using the statistical software IBM SPSS Statistics version 25.0. $p$ values smaller than 0.05 were considered statistically significant.

\section{Ethical considerations}

Before embarking on the study, written permissions were obtained from the administrations of the universities whose students were to be included in the study's sample. Written approval was obtained from the author's Sakarya University Ethics Committee (Approval no: 71522473/050.01.04.101).

\section{RESULTS}

The sociodemographic characteristics of the students who par- 
ticipated in the study are given in Table 1 . The mean age of the participants was 21.6 \pm 1.38 . Among the participants, $64.8 \%$ were students in the nursing department, 53.4\% were third-year students, $84.6 \%$ were female, $41.6 \%$ had graduated from Anatolian High Schools (high schools where education is provided in English, French, or German), 87.9\% were unemployed, 76.0\% were satisfied with the profession, $74.4 \%$ wanted to improve themselves professionally, the mothers and fathers of $66.9 \%$ and

Table 1. Sociodemographic Characteristics of Nursing and Midwifery Students

$(N=736)$

\begin{tabular}{|c|c|c|c|}
\hline Variables & $\mathrm{M} \pm \mathrm{SD}$ & $\mathrm{n}$ & $\%$ \\
\hline Age (yr) & $21.6 \pm 1.38$ & & \\
\hline The number of siblings & $2.60 \pm 1.71$ & & \\
\hline \multicolumn{4}{|l|}{ Department } \\
\hline Nursing & & 477 & 64.8 \\
\hline Midwifery & & 259 & 35.2 \\
\hline \multicolumn{4}{|l|}{ Grade } \\
\hline $3^{\text {rd }}$ grade & & 393 & 53.4 \\
\hline $4^{\text {th }}$ grade & & 343 & 46.6 \\
\hline \multicolumn{4}{|l|}{ Gender } \\
\hline Man & & 113 & 15.4 \\
\hline Woman & & 623 & 84.6 \\
\hline \multicolumn{4}{|l|}{ High school education } \\
\hline Medical vocational high school & & 127 & 17.3 \\
\hline Anatolian high school & & 306 & 41.6 \\
\hline Vocational high school & & 69 & 9.3 \\
\hline Regular high school & & 234 & 31.8 \\
\hline \multicolumn{4}{|l|}{ Mother's education status } \\
\hline Illiterate & & 68 & 9.2 \\
\hline Primary school & & 492 & 66.9 \\
\hline High school & & 142 & 19.3 \\
\hline Associate's or bachelor's degree & & 34 & 4.6 \\
\hline \multicolumn{4}{|l|}{ Father's education status } \\
\hline Illiterate & & 24 & 3.2 \\
\hline Primary school & & 356 & 48.4 \\
\hline High school & & 264 & 35.9 \\
\hline Associate's or bachelor's degree & & 92 & 12.5 \\
\hline \multicolumn{4}{|l|}{ Employment status } \\
\hline Employed & & 89 & 12.1 \\
\hline Not employed & & 647 & 87.9 \\
\hline \multicolumn{4}{|l|}{ Satisfaction with the profession } \\
\hline Yes & & 559 & 76.0 \\
\hline No & & 177 & 24.0 \\
\hline \multicolumn{4}{|c|}{ Considering to progress in the profession } \\
\hline Yes & & 547 & 74.4 \\
\hline No & & 189 & 25.6 \\
\hline Total & & 736 & 100.0 \\
\hline
\end{tabular}

$\mathrm{M}=$ Mean; SD=Standard deviation.
$48.4 \%$ of the students, respectively, had primary level education (Table 1).

In this study, the mean scores that the participants obtained from the CCIMQ, SES, and PSI were 9.36 \pm 3.56 , 85.94 \pm 10.26 , and $114.43 \pm 17.56$, respectively. The mean scores that the participants obtained from the subscales of SES were as follows: starting to display the behavior: $32.21 \pm 3.79$; maintaining the behavior: 27.44 \pm 3.34 ; completing the behavior: 17.07 \pm 3.90 ; and struggling against barriers: $9.21 \pm 2.41$. The mean scores that the participants obtained from the subscales of PSI were as follows: confidence: $34.66 \pm 8.71$; approach/avoidance: $52.17 \pm 9.86$; and personal control: $20.64 \pm 3.37$. The lowest mean score was obtained from the personal control subscale (20.64 \pm 3.37$)$, a significant determinant for effective and successful problem-solving skills in a given situation.

According to the results of the Pearson's correlation analysis, the participants' mean CCIMQ score positively correlated with their mean SES score and year at school on a moderate level $(\mathrm{r}=.25, p<.001 ; \mathrm{r}=.11, p=.046)$. However, CCMQ negatively correlated with their mean PSI score and satisfaction with the profession on a moderate level $(\mathrm{r}=-.21, p<.001 ; \mathrm{r}=-.13, p<.001)$ (Table 2). In other words, because a low PSI score indicates that the person's problem-solving skill is high, as the problem-solving skill improved, so did the CCIMQ score.

Table 2. Correlation between CCIMQ, SES and PSI $\quad(N=736)$

\begin{tabular}{|c|c|c|c|}
\hline \multirow{2}{*}{ Scales } & \multirow{2}{*}{ Subscales } & \multicolumn{2}{|c|}{ CCIMQ } \\
\hline & & $r^{+}$ & $p$ \\
\hline SES & Starting to display the behavior & .23 & $<.001$ \\
\hline SES & Maintaining the behavior & .18 & $<.001$ \\
\hline SES & Completing the behavior & .22 & $<.001$ \\
\hline SES & Struggling against barriers & .12 & .045 \\
\hline SES & Total & .25 & $<.001$ \\
\hline PSI & Confidence & -.17 & $<.001$ \\
\hline PSI & Approach/avoidance & -.22 & $<.001$ \\
\hline PSI & Personal control & -.06 & $<.136$ \\
\hline PSI & Total & -.21 & $<.001$ \\
\hline $\begin{array}{l}\text { Satisfaction with } \\
\text { the profession }\end{array}$ & & -.13 & $<.001$ \\
\hline Year at school & & .11 & .046 \\
\hline Gender & & .08 & .055 \\
\hline
\end{tabular}

CCIMQ=Catheter Care and Infiltration Monitoring Questionnaire; PSI= Problem-solving Inventory; SES=Self-Efficacy Scale.

'Pearson's correlation coefficient. 
Table 3. Multiple Regression Analysis between CCIM, SES, PSI (N=736)

\begin{tabular}{|c|c|c|c|c|c|}
\hline Independent variables & $\beta$ & $\begin{array}{l}\text { Stand- } \\
\text { ardized } \\
\text { beta } \\
\text { weight }\end{array}$ & $\mathrm{t}$ & $\mathrm{F}$ & $p$ \\
\hline Constant & 6.48 & & 4.19 & 21.64 & .001 \\
\hline SES & 0.07 & .21 & 5.77 & & \\
\hline PSI & -0.02 & -.15 & -4.15 & & \\
\hline $\begin{array}{l}\text { Satisfaction with the } \\
\text { profession }\end{array}$ & -0.76 & .29 & 2.59 & & \\
\hline Year at school & 0.76 & .25 & 3.06 & & \\
\hline \multicolumn{6}{|c|}{$R^{2}=.10 ;$ Adjusted $R^{2}=.10$} \\
\hline
\end{tabular}

Dependent variable: Catheter care and infiltration monitoring score. CCIMQ=Catheter Care and Infiltration Monitoring Questionnaire; PSI= Problem-solving Inventory; SES=Self-Efficacy Scale.

As shown in Table 3, the results of the analysis of variance $\left(\mathrm{F}_{\mathrm{SES}} \mathrm{SES}_{-\mathrm{PSI}} \mathrm{PSI}=21.64\right)$ were significant on the level of $p<.001$. That the results of the variance analysis were significant indicates that the relationship between the dependent and independent variables was linear and statistically significant. The SES, PSI, year at school, and satisfaction with the profession, in combination, predicted the mean score for the CCIMQ by $10.0 \%$ $\left(\mathrm{R}^{2}=.10\right)$.

While the SES total score and the "year at school" variable predicted the success of the CCIMQ significantly and positively, the PSI total score and the "satisfaction with the profession" variable predicted it negatively. As the PSI score increased, so did the ability to cope with problems.

\section{DISCUSSION}

Our literature review demonstrated that the literature lacked tools for a validated peripheral intravenous assessment, problem-solving, and self-efficacy specific to nursing students. In this study, $64.2 \%$ of the participants had sufficient knowledge about catheter care and infiltration monitoring. The review of the literature related to the issue showed that, although there were not many studies on students, studies on the infiltration knowledge levels of the nurses ranged between 5.0\% and 75.9\% [5,24-26]. Cicolini et al. [6] and Woody and Davis [27] determined that students' possession of good knowledge levels reduced the development of peripheral venous catheter-related infections. In their study conducted with nursing students, Prasanna and Radhika
[24] found that $66.7 \%$ of the students had sufficient knowledge.

Similar to our study, Simonetti et al.'s study [26] on nursing students showed that the knowledge of one third of the nursing students on PIVC was insufficient. In this study, although the knowledge level of the participants was similar to the average level in the literature, it was higher than the levels in some studies, probably because our study was conducted with third- and fourth-year students. These students are more experienced than are first- and second-year students and they perform PIVC practices more frequently.

Among the participants, the mean SES score was 114.43 \pm 17.56. While the subscale with the highest score was the "starting to display the behavior" subscale which is an important determinant in the development and maintenance of behavior (32.21 \pm 3.79), the subscale with the lowest score was the "struggling against barriers" subscale $(9.21 \pm 2.41)$. The high self-efficacy score obtained by the participants was regarded as a positive result. It is assumed that a high level of self-efficacy in nursing will provide a high level of thinking efficacy, will contribute to problem-solving skills that enable nurses to find effective solutions, and, thus, will increase the quality of the care that is given $[7,28]$. Effective problem-solving strategies and decision-making capability based on strong and accurate knowledge are a process, which is the focus of the nursing practices expected from a professional nurse [29]. Therefore, nurses' problem-solving skills should be evaluated and developed during their professional training. In this study, the mean score that the participants obtained from the PSI $(114.43 \pm 17.56)$ was moderate. A high PSI score positively affects an individual's ability to cope with problems. Similarly, in Zhang et al.'s [7] and Kantek et al.'s [11] studies, the participants' PSI scores were moderate. Good and strong problem-solving skills may enable nurses to cope with problems, provide healthy solutions, and, thus, improve the quality of the healthcare they offer. The score obtained from PSI indicates how effective and successful a person is in solving problems. Therefore, the moderate score that the participants obtained from PSI suggested that their problem-solving skills should be improved.

Although a considerable number of studies have focused on PIVC and its complications [4,30], rather less attention has been paid to the relationship between PIVC and knowledge and skills 
$[5,7,31,32]$. In our study, we also investigated the relationship between problem-solving skills and self-efficacy for the first time. The participants' catheter care and infiltration monitoring knowledge scores increased as their PSI scores increased. Similar to this study, the studies by Engström and Forsberg [33], Kantek and Yeşilbaş [11], Karadağ et al. [12], and Kim and Kim [28], found that as the participants' self-efficacy levels increased, so did their success levels. Similarly, as in this study, literature previous studies found that students' catheter care and infiltration knowledge increased parallel to the increase in their self-efficacy scores and experience $[5,8,25]$. The clinical environment provides students with self-confidence, practice skills, and professionalism and it enables them to experience successful clinical learning [8]. Nurses with high levels of self-confidence, self-efficacy, and problem-solving skills were reported to be more successful [7].

This cross-sectional study yielded results on students' PIVC knowledge, the duration of their education, and their satisfaction with the profession. Similarly, in their study, Simonetti et al. [26] found that the duration of education and satisfaction with the profession were related to the participating students' PIVC knowledge. This was probably because the education that the students received increased their knowledge levels, and those who were satisfied with their professions were more interested in issues related to their professions. For example, Günay İsmailoğlu et al. [34] found that students' satisfaction with their profession positively influenced their knowledge levels.

One of the strengths of this study is the large sample size and the multicenter faculty setting. Another strength of the study is that it is one of the first few studies conducted in Turkey in which the relationship between catheter care and infiltration monitoring status and PSI and SES is addressed. The data were collected by equally trained researchers for each structure. However, one limitation of the study was that students at only two faculties participated. Thus, the results of this study cannot be generalized to all students.

\section{CONCLUSION}

The most significant result of our study is its determination that the variables of self-efficacy, problem-solving, liking the profession and year of study predict catheter care and infiltration monitoring levels. The score in the Catheter Care and Infiltration Monitoring Questionnaire increases by the increase in self-efficacy, problem-solving skills, profession increases, years of study. It may be recommended to monitor students in terms of self-efficacy, improve the self-efficacy perceptions of students with low self-efficacy and establish programs for assessing and improving the self-efficacy levels of students who are determined to be excessively stressed in the clinical practice environment. Additionally, it is important to help students participate in planned experiences and decision-making processes where they will apply the steps of problem-solving for the purpose of developing their problem-solving perceptions in the positive direction. In addition to it is recommended for opportunities for students to put their knowledge into practice to be improved. In the study, the participants' knowledge on catheter care and infiltration was above average. The students who had high levels of self-efficacy, practice opportunities and clinical skills also had high knowledge levels. This study provides reliable and valid data for a general understanding of the status of nursing students of being successful in catheter care and infiltration prevention. Discussion for advances in nursing practice and nursing education is strongly recommended. Considering the limitation of this study, there is a need for more comprehensive studies with larger samples in the future.

\section{CONFLICTS OF INTEREST}

The authors declared no conflict of interest.

\section{ACKNOWLEDGEMENTS}

The authors wish to acknowledge the students who agree to participate in the research and the faculty administrations that gave permission for the research.

\section{AUTHOR CONTRIBUTIONS}

\section{Conceptualization or/and Methodology: Dogu Kokcu O.}

Data curation or/and Analysis: Dogu Kokcu O \& Cevik C.

Funding acquisition: Dogu Kokcu O \& Cevik C. Investigation: Dogu Kokcu O \& Cevik C. 
Project administration or/and Supervision: Dogu Kokcu O \& Cevik C.

Resources or/and Software: Dogu Kokcu O.

Validation: Dogu Kokcu O \& Cevik C.

Visualization: Dogu Kokcu O \& Cevik C.

Writing original draft or/and Review \& editing: Dogu Kokcu O \& Cevik C.

\section{REFERENCES}

1. Danski MTR, Johann DA, Vayego SA, de Oliveira GRL, Lind J. Complications related to the use of peripheral venous catheters: A randomized clinical trial. Acta Paulista de Enfermagem. 2016;29(1):84-92 https://doi.org/10.1590/1982-0194201600012

2. Miliani K, Taravella R, Thillard D, Chauvin V, Martin E, Edouard S, et al. Peripheral venous catheter-related adverse events: Evaluation from a multicentre epidemiological study in France (the CATHEVAL project). PloS One. 2017;12(1):e0168637. https://doi.org/10.1371/journal.pone.0168637

3. Lv L, Zhang J. The incidence and risk of infusion phlebitis with peripheral intravenous catheters: A meta-analysis. The Journal of Vascular Access. 2020;21(3):342-349.

4. Suliman M, Saleh W, Al-Shiekh H, Taan W, AlBashtawy M. The incidence of peripheral intravenous catheter phlebitis and risk factors among pediatric patients. Journal of Pediatric Nursing. 2020;50:89-93.

https://doi.org/10.1016/j.pedn.2019.11.006

5. Ahlin C, Klang-Söderkvist B, Johansson E, Björkholm M, Löfmark A. Assessing nursing students' knowledge and skills in performing venepuncture and inserting peripheral venous catheters. Nurse Education in Practice. 2017;23:8-14.

https://doi.org/10.1016/j.nepr.2017.01.003

6. Cicolini G, Simonetti V, Comparcini D, Labeau S, Blot S, Pelusi G, et al. Nurses' knowledge of evidence-based guidelines on the prevention of peripheral venous catheter-related infections: A multicentre survey. Journal of Clinical Nursing. 2014;23:2578-2588. https://doi.org/10.1111/jocn.12474

7. Zhang XH, Meng LN, Liu HH, Luo RZ, Zhang CM, Zhang PP, et al. Role of academic self-efficacy in the relationship between self-directed learning readiness and problem-solving ability among nursing students. Frontiers of Nursing. 2018;5(1) :7581. https://doi.org/10.1515/fon-2018-0011

8. Eraydın Ş, Karagözoğlu Ş. Investigation of self-compassion, self-confidence and submissive behaviors of nursing students studying in different curriculums. Nurse Education Today. 2017;54:44-50. https://doi.org/10.1016/j.nedt.2017.03.007
9. Hamilton CL. Progression of clinical self-efficacy among baccalaureate nursing students [dissertation]. Minneapolis (MN): Walden University; 2018. p. 1-95.

10. Al Zu'bi MAKM, Shawabka GAF. Assessment of stress factors for nursing student toward training in the critical areas of Princess Basma Hospital. The Journal of Middle East and North Africa Sciences. 2018;4:8-12. https://doi.org/10.12816/0045801

11. Kantek F, Yeşilbaş H. The effects of gender on problem solving skills of nursing students in Turkey: A meta-analysis study. Journal of Human Sciences. 2019;16(1):134-142. Turkish. https://doi.org/10.14687/jhs.v16i1.5451

12. Karadağ M, Alpaslan Ö, Şişman NY, İşeri ÖP. Problem solving skills and epistemological beliefs of nursing and midwifery students. Cukurova Medical Journal. 2018;43(1):1-6. Turkish. https://doi.org/10.17826/cumj.340081

13. Çelenk O, Topoyan M. Analysis of problem solving skill levels of nurses working in a university hospital. Dokuz Eylül Üniversitesi Hemşirelik Fakültesi Elektronik Dergisi. 2017;10(4) :251259. Turkish

14. Karadağ E, Aksoy Derya Y, Ucuzal M. The self-efficacy-sufficiency levels of a health college student. Maltepe Üniversitesi Hemşirelik Bilim ve Sanatı Dergisi. 2011;4(1) :13-20. Turkish.

15. McGowan D. Peripheral intravenous cannulation: Managing distress and anxiety. British Journal of Nursing. 2014;23 Suppl 19:S4-S9. https://doi.org/10.12968/bjon.2014.23.Sup19.S4

16. Faul F, Erdfelder E, Buchner A, Lang AG. Statistical power analyses using G*Power 3.1: Tests for correlation and regression analyses. Behavior Research Methods. 2009;41(4) :11491160. https://doi.org/10.3758/BRM.41.4.1149

17. Sherer M, Maddux JE, Mercandante B, Prentice-Dunn S, Jacobs B, Rogers RW. The self-efficacy scale: Construction and validation. Psychological Reports. 1982;51(2):663-671. https://doi.org/10.2466/pr0.1982.51.2.663

18. Sherer M, Adams CH. Construct validation of the self-efficacy scale. Psychological Reports. 1983;53(3):899-902. https://doi.org/10.2466/pr0.1983.53.3.899

19. Gözüm S. Construct validation of Turkish form of the self efficacy scale; the relationship between self efficacy perception of cope with stress. Journal of Anatolia Nursing and Health Sciences. 1999;2(1):35-43. Turkish.

20. Maitland A, Presser S. A comparison of five question evaluation methods in predicting the validity of respondent answers to factual items. In: Beatty P, Collins D, Kaye L, Padilla JL, Willis GB, Wilmot A, editors. Advances in questionnaire design, development, evaluation and testing. Proceedings of the 2nd Conference on Questionnaire Design, Development, Evaluation, and Testing (QDET2); 2016 Nov 9-13; Miami (FL), USA. Hoboken (NJ): Wiley; 2020. p. 75-90.

21. Taber KS. The use of Cronbach's alpha when developing and reporting research instruments in science education. Research 
in Science Education. 2018;48(6) :1273-1296.

https://doi.org/10.1007/s11165-016-9602-2

22. Heppner PP, Petersen $\mathrm{CH}$. The development and implications of a personal problem-solving inventory. Journal of Counseling Psychology. 1982;29(1):66-75. https://doi.org/10.1037/0022-0167.29.1.66

23. Taylan S. Adapting Heppner's problem solving inventory, reliability and validity study [master's thesis]. Ankara: Ankara University; 1990. p. 1-65. Turkish.

24. Prasanna K, Radhika M. Knowledge regarding catheter care among staff nurses. International Journal of Applied Research. 2015;1(8):182-186.

25. Qamar Z, Afzal M, Kousar R, Waqas A, Gilani SA. Assess nurses knowledge and practices towards care and maintenance of peripheral intravenous cannulation in Services Hospital Lahore, Pakistan. Saudi Journal of Medical and Pharmaceutical Sciences. 2017;3(6B) :608-614.

26. Simonetti V, Comparcini D, Miniscalco D, Tirabassi R, Di Giovanni P, Cicolini G. Assessing nursing students' knowledge of evidence-based guidelines on the management of peripheral venous catheters: A multicentre cross-sectional study. Nurse Education Today. 2019;73:77-82. https://doi.org/10.1016/j.nedt.2018.11.023

27. Woody G, Davis BA. Increasing nurse competence in peripheral intravenous therapy. Journal of Infusion Nursing. 2013;36(6) :413-419. https://doi.org/10.1097/NAN.0000000000000013

28. Kim Y, Kim Y. The influence of academic self-efficacy, and critical thinking disposition on problem solving ability of nursing students. Journal of the Korea Academia-Industrial cooperation Society. 2016;17(9):589-598.
https://doi.org/10.5762/KAIS.2016.17.9.589

29. Spence D, Zambas S, Mannix J, Jackson D, Neville S. Challenges to the provision of clinical education in nursing. Contemporary Nurse. 2019;55(4-5):458-467. https://doi.org/10.1080/10376178.2019.1606722

30. Carr PJ, Higgins NS, Cooke ML, Rippey J, Rickard CM. Tools, clinical prediction rules, and algorithms for the insertion of peripheral intravenous catheters in adult hospitalized patients: A systematic scoping review of literature. Journal of Hospital Medicine. 2017;12(10):851-858. https://doi.org/10.12788/jhm.2836

31. Keleekai NL, Schuster CA, Murray CL, King MA, Stahl BR, Labrozzi LJ, et al. Improving nurses' peripheral intravenous catheter insertion knowledge, confidence, and skills using a simulation-based blended learning program: A randomized trial. Simulation in Healthcare. 2016;11(6):376-384. https://doi.org/10.1097/SIH.0000000000000186

32. Zhao FF, Lei XL, He W, Gu YH, Li DW. The study of perceived stress, coping strategy and self-efficacy of Chinese undergraduate nursing students in clinical practice. International Journal of Nursing Practice. 2015;21(4):401-409. https://doi.org/10.1111/ijn.12273

33. Engström Å, Forsberg A. Peripheral intravenous catheter difficulty - a clinical survey of registered nurse and critical care nurse performance. Journal of Clinical Nursing. 2019;28(34):686-694. https://doi.org/10.1111/jocn.14668

34. Günay İsmailoğlu E, Zaybak A. Comparison of the effectiveness of a virtual simulator with a plastic arm model in teaching intravenous catheter insertion skills. Computers, Informatics, Nursing. 2018;36(2):98-105. https://doi.org/10.1097/CIN.0000000000000405 